\title{
Conducting tissues in congenitally corrected transposition with situs inversus
}

\author{
JAMES L. WILKINSON, AUDREY SMITH, CHRISTOPHER LINCOLN, \\ AND ROBERT H. ANDERSON ${ }^{1}$ \\ From the Institute of Child Health, University of Liverpool, and the Cardiothoracic Institute, \\ Brompton Hospital, London
}

Three cases of congenitally corrected transposition in situs inversus individuals were characterised by visceroatrial situs inversus, atrioventricular discordance, and ventriculoarterial discordance: one case was studied clinically, and the other 2 were necropsy specimens. The disposition of the atrioventricular conducting tissues was established in each case, in the living patient by intraoperative mapping, and in the necropsy specimens by histopathological investigation. In all, the connecting atrioventricular bundle arose from a normally situated posterior atrioventricular node, normally related to the landmarks of the atrial septum. Though anterior nodes were identified in the necropsy specimens, as reported in congenitally corrected transposition in situs solitus individuals, they differed from those in the latter situation in that they made no atrioventricular connection. These findings have obvious surgical importance. It is suggested that the posterior connection is related to the good septal alignment in these cases which lacked significant septal defects. Posterior connections are not necessarily present in all situs inversus individuals with corrected transposition, particularly when there are malalignment ventricular septal defects : further studies are required in such cases.

In earlier papers we have described the disposition of the conducting tissue in 11 specimens of congenitally corrected transposition (Anderson et al., $1973,1974 b)$. In all 11 cases the sequential arrangement was situs solitus, atrioventricular discordance, and l-transposition (Shinebourne et al., 1976). Abnormal anterior atrioventricular nodes and bundles were identified in all the specimens studied. We were also able to demonstrate a posterior node in each case in its expected situation in the atrial septum. The latter, however, effected an atrioventricular connection in only 1 of the 11 cases, and in this case an anterior connection was additionally present. A posterior connection had previously been described by Lev et al. (1963) who also observed a 'unique' anterior extension of the bundle. On the basis of these findings we suggested that, even if a posterior connection were present in corrected transposition, an anterior node and bundle were also to be expected (Anderson et al., 1974b).

We have recently had the opportunity of studying three examples of congenitally corrected transposition in patients with total visceroatrial situs inversus (situs inversus, atrioventricular discordance, and ${ }^{1}$ R.H.A. is a British Heart Foundation Senior Research Fellow. Received for publication 23 March 1977 $d$-transposition). Two of the patients had died and the hearts were available for histological examination. The third was studied during life using electrophysiological techniques (Kaiser et al., 1970). Our observations conformed with our previous hypothesis regarding the presence of both anterior and posterior nodes. However, there were variations of considerable clinical and surgical significance: in particular, we found that the posterior node was more likely to be the connecting node in this variety of corrected transposition, as has been reported recently by Dick et al. (1977) and Thiene et al. (1977).

\section{Subjects and methods}

The two necropsy specimens (cases 1 and 2) came from the collection of the Royal Liverpool Children's Hospital. After morphological study and photography, tissue blocks were taken for histology. The blocks comprised the lower part of the interatrial septum and the upper part of the ventricular septum, and incorporated the roots of both the aorta and the pulmonary artery. The blocks were embedded in paraffin wax and sectioned in the frontal plane. All sections (10 $\mu$ thick) were retained in 
cardboard trays (Smith et al., 1977) and 1 section in 50 was initially mounted and stained using Masson's trichrome technique. After microscopical examination additional sections were mounted and stained as required.

The living patient (case 3) was studied and operated on at the Brompton Hospital, London.

\section{Case reports}

\section{CASE 1}

A Caucasian male infant was born at 38 weeks' gestation (weight $3798 \mathrm{~g}$ ). He was noted to have a murmur shortly after birth and his pulse was found to be irregular at the age of 10 days. His electrocardiogram at one day showed sinus rhythm. Chest $x$-ray examination showed isolated laevocardia. He fed and gained weight normally. At 8 months an electrocardiogram showed heart block but he remained asymptomatic until the age of 14 months when he had a convulsion. He was admitted to hospital and 2 weeks later had a severe Adams-Stokes attack. He died at the age of 16 months in ventricular fibrillation.

Necropsy (Dr. P. Laidler) showed visceroatrial situs inversus with a 'normal' right sided spleen. The left lung was trilobed and the right lung was bilobed.

The heart was left sided and the apex was to the left. The aorta was anterior and to the right of the pulmonary artery (Fig. 1). The venae cavae (left sided) both drained to the left-sided atrium, which was a morphologically right atrium, exhibiting a crista terminalis and also receiving the coronary sinus (Fig. 2B). The foramen ovale was closed. The pulmonary veins drained to the right sided atrium, which was a morphologically left atrium (Fig. 2A). The morphologically right atrium (left sided) drained to a left sided morphologically left ventricle through a bicuspid atrioventricular valve whose papillary muscle pattern was typical of the normal mitral valve (Fig. 2D). The pulmonary artery arose posteriorly from the morphologically left ventricle, pulmonary-mitral valvar fibrous continuity being present. The interventricular component of the membranous septum was intact, but an aneurysm of this septum herniated into the pulmonary outflow tract, producing anatomical obstruction (Fig. 2D). The right sided morphologically left atrium drained through the right atrioventricular valve to the morphologically right ventricle (right sided) (Fig. 2C). The ventricle was coarsely trabeculated with the trabecula septomarginalis on its septal surface, and the atrioventricular valve was tethered within the ventricle by papillary muscles typical of the normal tricuspid valve (Fig. 2C). The aorta arose anteriorly from the morphologically right ventricle (Fig. 2C). The coronary arteries arose from the two septal aortic sinuses, and the right coronary artery was dominant. The left coronary artery gave rise to the anterior descending coronary artery. The pathological diagnosis was: (1) situs inversus, atrioventricular discordance, $d$-transposition; (2) pulmonary outflow tract obstruction (aneurysm of membranous septum).

\section{Histological findings}

The tendon of Todaro was well formed, and formed the anticipated triangle with the atrioventricular valve annulus (Fig. 3). At the apex of that triangle was situated the posterior node. The compact portion of the node was hypoplastic and only short segments of transitional cells were identified (Fig. 4A). The node did not penetrate the annulus fibrosus, being confined to the atrial side of the central fibrous body. However, a well-formed penetrating atrioventricular bundle was identified within the central fibrous body (Fig. 4B), but this did not make contact with the posterior node. The two were closely adjacent, but were always separated by the annulus fibrosus (Fig. 3). The penetrating bundle descended to the crest of the ventricular septum, where it divided beneath the aneurysmal membranous septum, a fan-like left bundle-branch descending into the morpholo-

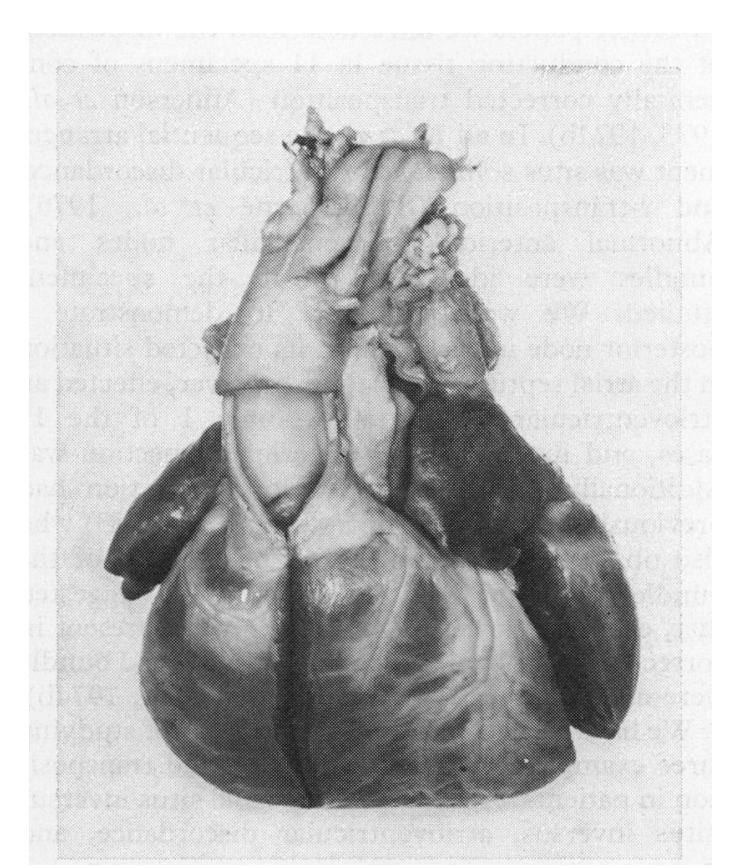

Fig. 1 Anterior view of specimen from case 1. 
gically left ventricle and a cord-like right bundlebranch being distributed to the morphologically right ventricle beneath the cover of the trabecula septomarginalis. The atrioventricular bundle then continued beyond the division, and ascended in front of the membranous septum as an anterior bundle (Fig. 3). However, the anterior bundle faded out in the pulmonary outflow tract and did not reach the area of pulmonary-mitral fibrous continuity. Anterior to the tendon of Todaro, a second small area of specialised cells was identified within the atrial septum (Fig. 4C). However, this anterior node made no contact with ventricular myocardium.
CASE 2

A Caucasian male infant born at 37 weeks' gestation (weight $3004 \mathrm{~g}$ ). He was cyanosed and dyspnoeic from birth, and was admitted to the Royal Liverpool Children's Hospital on the first day of life. He was noted to have dextrocardia. Electrocardiogram showed sinus rhythm with a $\mathrm{P}$ wave axis of $+100^{\circ}$, QRS axis of $+60^{\circ}$, and essentially normal $Q R S$ morphology; $Q$ waves were not present in any of the praecordial leads. Before full investigation could be carried out, he deteriorated rapidly and died.

Necropsy showed visceral situs inversus; the viscera were normal in all other respects, a normal

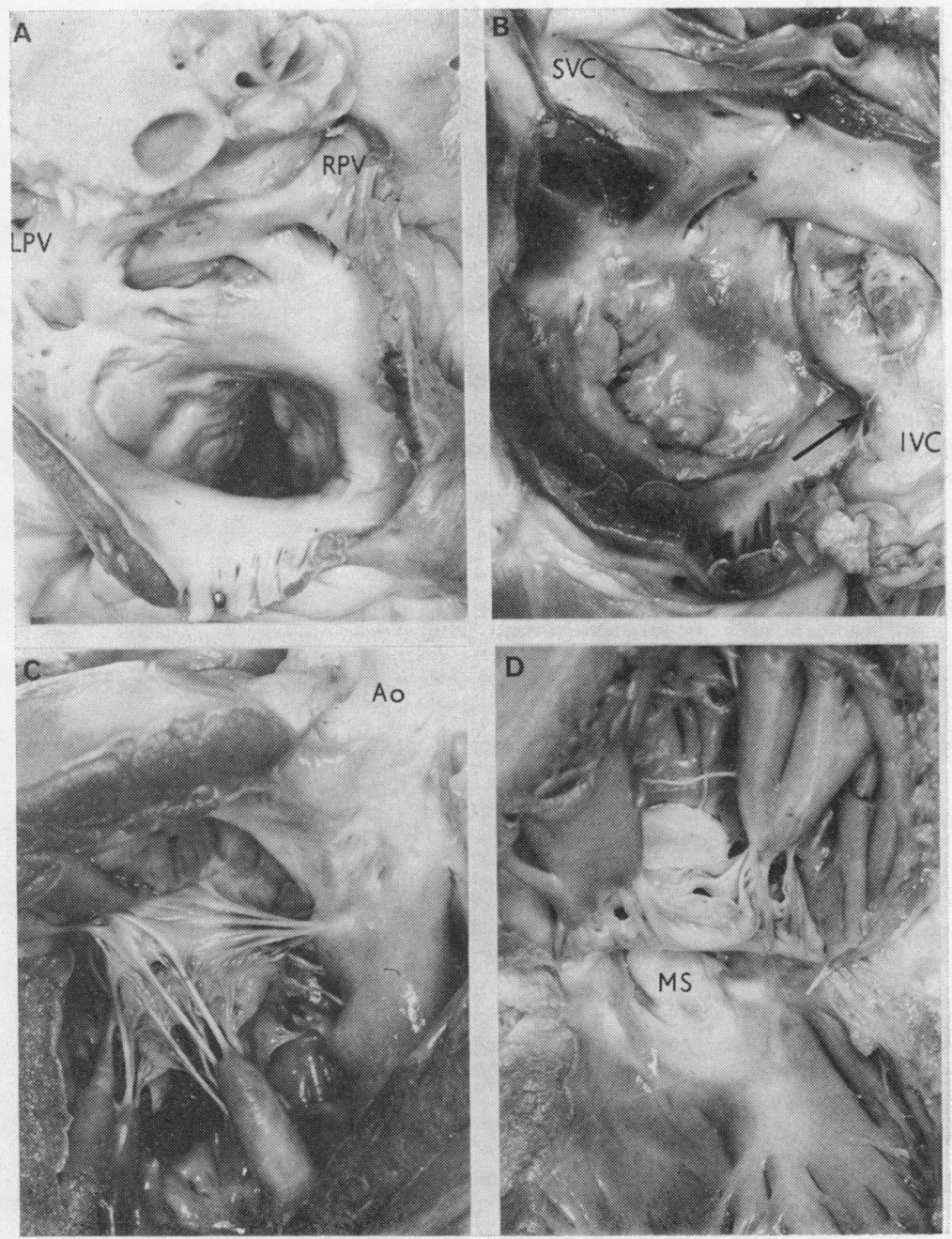

Fig. 2 (A) Morphological left atrium from case 1, viewed from above and behind. $R P V$, right pulmonary veins; $L P V$, left pulmonary veins. (B) Morphological right atrium (case 1) with IVC and SVC laid open. Arrow indicates opening of coronary sinus. (C) Morphological right ventricle (case 1) showing tricuspid valve and aortic valve. Ao, aorta. (D) Morphological left ventricle (case 1) viewed from apex, to show outflow tract to pulmonary artery. MS, aneurysmal membranous septum. 
spleen being present in the right hypochondrium. The right lung was bilobed and the left lung was trilobed. The aorta arose anteriorly and to the right of the pulmonary artery. The superior vena cava and inferior vena cava both drained to the left sided atrium which showed moderate endocardial fibroelastosis and had all the characteristics of a morphologically right atrium except that a coronary sinus was not present. A left coronary vein drained directly into the posterior part of the atrium. The fossa ovalis was well formed and the foramen ovale was patent, with a patulous septum primum. The pulmonary veins drained to the right sided atrium which had the appearances of a morphologically left atrium. A right coronary vein drained directly into the posterior wall of this atrium. The

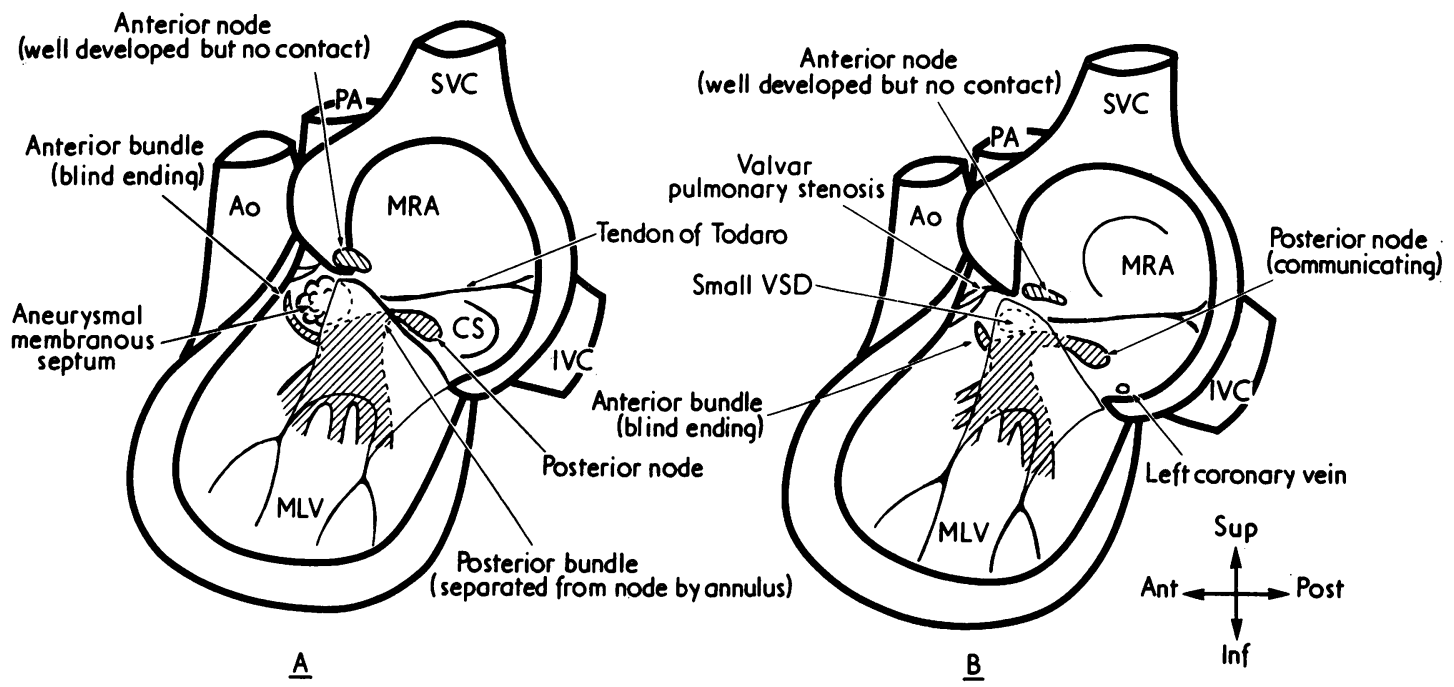

Fig. 3 Diagrams to show morphology and conducting tissue in cases 1 and 2. (A) Case 1. Viewed from left side with parietal wall of morphological right atrium $(M R A)$ and morphological left ventricle $(M L V)$ removed (compare with Fig. $2 B$ and D). (B) Similar view of case 2. CS, coronary sinus; Ao, aorta; $P A$, pulmonary artery; SVC, superior vena cava; IVC, inferior vena cava; VSD, ventricular septal defect.
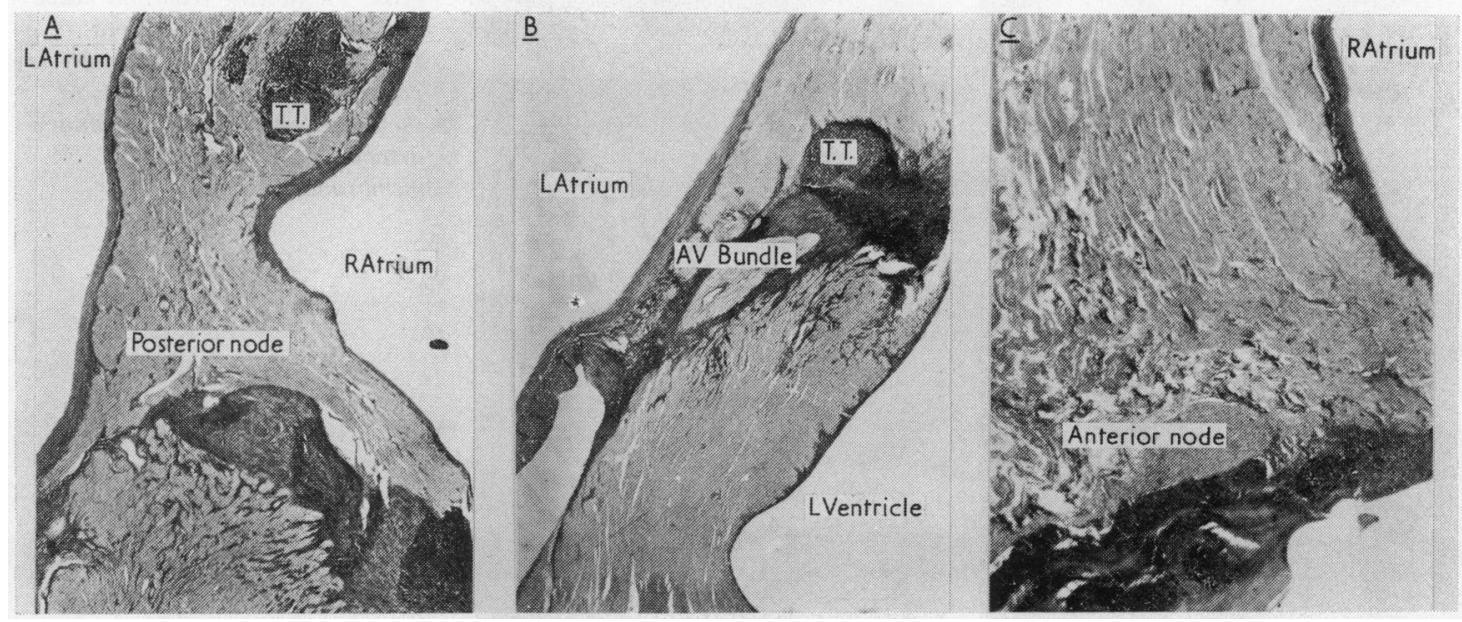

Fig. 4 Photomicrographs of sections from case 1. (A) Posterior node; (B) bundle of His; (C) anterior node. TT, tendon of Todaro. 
morphologically right atrium, left sided, drained through a biscuspid atrioventricular valve into a left sided morphologically left ventricle. This ventricle was grossly hypertrophied with pronounced endocardial fibroelastosis and gave rise to the posteriorly situated pulmonary artery. Critical pulmonary valve stenosis was present, the valve having a pin-point orifice. Just below the pulmonary valve was a minute ventricular septal defect measuring less than $1 \mathrm{~mm}$ in diameter. The morphologically left atrium, right sided, drained through a tricuspid valve to a morphologically right ventricle on the right. This ventricle gave rise to the anteriorly situated, right sided aorta. The aortic arch was left sided but a right sided ductus arose from the origin of the right subclavian and was patent. The pathological diagnosis was: (1) situs inversus, atrioventricular discordance, $d$-transposition; (2) minute ventricular septal defect; (3) critical pulmonary valve stenosis; (4) persistent ductus arteriosus; (5) endocardial fibroelastosis of the left sided atrium and ventricle.

\section{Histological findings}

Examination of the interatrial septum showed a left sided venous valve continuous with a left sided tendon of Todaro which inserted into the central fibrous body. A left sided atrioventricular node was identified at the apex of the triangle formed between the tendon and the atrioventricular valve annulus (Fig. 3). The node extended across the root of the interatrial septum (Fig. 5A) and gave rise to a right sided perforating bundle which passed through the

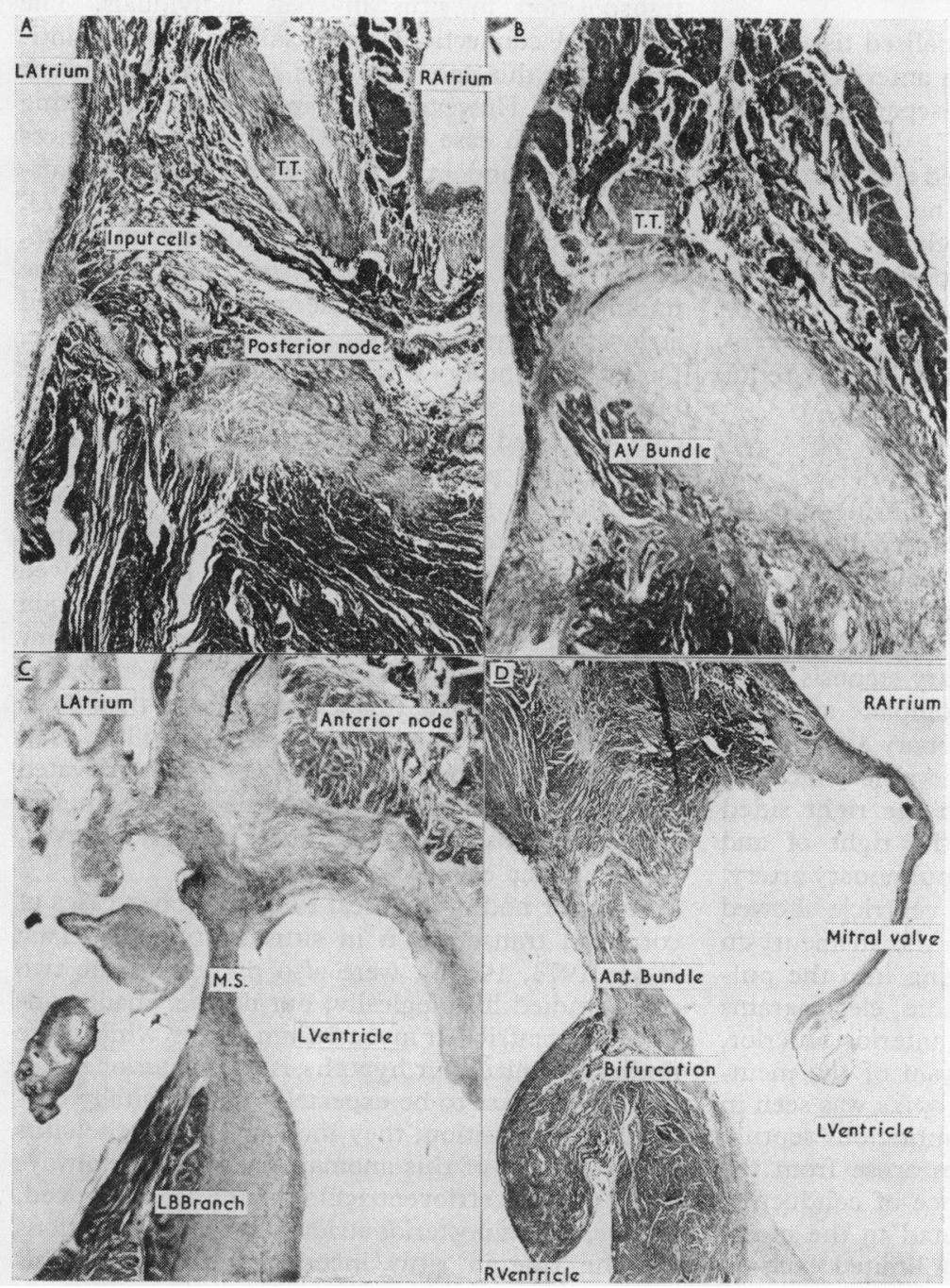

Fig. 5 Photomicrographs of sections from case 2. (A) Posterior node. (B) Connecting bundle. (C) Anterior node (note thickened endocardium in left ventricle overlying left bundle-branch); (D) Anterior bundle and bifurcation. TT, tendon of Todaro; $M S$, membranous septum. 
fibrous ring (Fig. 5B). After perforation, the bundle coursed along the upper edge of the ventricular septum from right to left, lying beneath the membranous septum (Fig. 5C). On the left side it gave rise to the fan-like ramifications of the left bundlebranch which lay deep to the greatly thickened endocardium (Fig. 5C). From this area a cord-like bundle ran forwards just below the ventricular septal defect on the left side of the septum and then ascended before passing to the right and becoming the right bundle-branch. As it ascended from left to right and became intramuscular, the right bundlebranch connected with a thick bundle of conducting tissue which ascended steeply in the anterior rim of the ventricular septal defect. This bundle (Fig. 5D) approached the fibrous ring close to the stenotic pulmonary valve but did not connect with atrial myocardium.

An additional collection of specialised tissue was identified in the interatrial septum anteriorly, lying just above the anterior bundle but separated from it by the annulus fibrosus (Fig. 5C). This anterior node was particularly well developed and was closely related to the pulmonary root. The anterior node was continuous posteriorly through the interatrial septum with the normally placed posterior node by way of a tenuous band of transitional atrial myocardium. It did not make contact with the ventricular myocardium except through the posterior node and bundle.

\section{CASE 3}

A 9-year-old boy was referred for consideration of surgical treatment of complex congenital heart disease with situs inversus and dextrocardia. He suffered from moderate exertional dyspnoea and cyanosis. Cardiac catheterisation had shown corrected transposition with pulmonary stenosis.

At operation the presence of complete atrial inversion was confirmed. The pulmonary artery arose posteriorly from the left sided ventricle which lay anteriorly. The aorta arose from the right sided posterior ventricle, and lay to the right of and slightly anterior to the root of the pulmonary artery. A ventriculotomy in the anterior ventricle showed that the major cause of obstruction was an aneurysm of the membranous septum bulging into the pulmonary outflow tract. His bundle electrograms showed His spikes in three sites, anterior, inferior, and posteroinferior to the aneurysm of the membranous septum. The earliest His spike was seen in the posteroinferior rim of the membranous septum and the latest of the three spikes arose from the anterior rim (Fig. 6). The presence of conducting tissue over such a large area related to the membranous septum meant that only a limited excision of the aneurysm could be attempted. This led to the creation of a small ventricular septal defect, which was oversewn. Since this did not produce adequate relief of obstruction, a porcine heterograft valved conduit (Hancock) was inserted between the ventriculotomy and the main pulmonary artery (end to side), leaving the outflow tract patent.

The patient made an uneventful recovery and remains in sinus rhythm.

The anatomical diagnosis was: (1) situs inversus, atrioventricular discordance, $d$-transposition; (2) pulmonary outflow tract obstruction (aneurysm of membranous septum).

\section{Discussion}

All 3 cases are examples of congenitally corrected transposition in situs inversus individuals. The segmental connections and relations were as anticipated for this anomaly (Ellis et al., 1952; Allwork et al., 1976). However, the disposition of conducting tissue in each case exhibited important differences from that found in patients with corrected transposition and situs solitus (Anderson et al., 1973, 1974b; Maloney et al., 1975; Kupersmith et al., 1974; Waldo et al., 1975). In each heart, the findings suggested that the normally positioned atrioventricular node was the connecting node. Direct continuity was shown with a posterior bundle in the second case. The findings in the first case suggested that the atrioventricular connection, known to be present at birth, was again posterior but had been severed with age, leading to the development of complete heart block. Use of intraoperative mapping in the third case again showed presence of a posterior connection. A His deflection was also recorded anterior to the aneurysmal membranous septum and close to the pulmonary valve. As the HV interval at this site was shorter than those seen posteriorly and inferiorly it seems likely that the anterior conducting pathway was activated retrogradely from below, suggesting that an anterior connection was absent. The latter cannot, however, be altogether excluded.

Anterior nodes, identical to those in our cases of corrected transposition in situs solitus (Anderson et al., 1973, 1974b), were also present in the two cases studied histologically, but neigher made contact with ventricular myocardium. Thus, while these findings confirm our hypothesis that anterior nodes and bundles are to be expected in congenitally corrected transposition, they indicate that in the situs inversus form of this anomaly these do not always make anterior atrioventricular connections. Indeed, it appears that posterior atrioventricular connections are the rule in situs inversus individuals. This 
observation is in keeping with previous reports on the conducting tissue in corrected transposition in situs inversus. Dick et al. (1977) localised the atrioventricular bundle posteriorly using electrophysiological techniques, while Thiene et al. (1977) have described findings similar to ours in two cases studied by histological techniques.

It is our opinion that the presence of a posterior connection rather than an anterior connection in these hearts is a consequence of the good alignment seen between the interatrial and the interventricular septum. In our case of corrected transposition in situs solitus with two connecting nodes, there was good septal alignment and we hypothesised that posterior connections should be anticipated in these circumstances. All cases presently studied had good alignment, two having intact septa and one a very small pinhole ventricular septal defect. Dick et al. (1977) suggested that the situation of the connection was dependent upon the type of bulboventricular loop present, anterior connections being associated with $d$-looping and posterior connections with $l$-looping. While this hypothesis is borne out by the present cases, and indeed is substantiated by a further case of a situs inversus heart with atrioventricular discordance and normally connected but malposed great arteries (Anderson et al., 1972), there are two important arguments against it. The first is that in primitive ventricle with outlet chamber, the connecting node is anterior whether the outlet chamber is right sided (presumed $d$ looping) or left sided (presumed $l$-looping) (Anderson et al., 1974a). The second is a theoretical argument: according to the concept of Dick et al. (1977) it would be necessary for an anterior connection to be present in the heart from a situs inversus individual with concordant atrioventricular connections and normal ventriculoarterial connections (mirror-image normal heart) since such a heart is formed as a consequence of $l$-bulboventricular looping. Clearly further studies are necessary to resolve this problem, and it is our intention to study further examples of corrected transposition in situs inversus, with malalignment of the atrial and ventricular septa. We would hesitate at this stage to predict a posterior connection in cases of corrected transposition in situs inversus with ventricular septal defect.

In conclusion, our investigation has shown that the disposition of the conducting tissue in the various forms of corrected transposition cannot be predicted with accuracy. It therefore behoves the

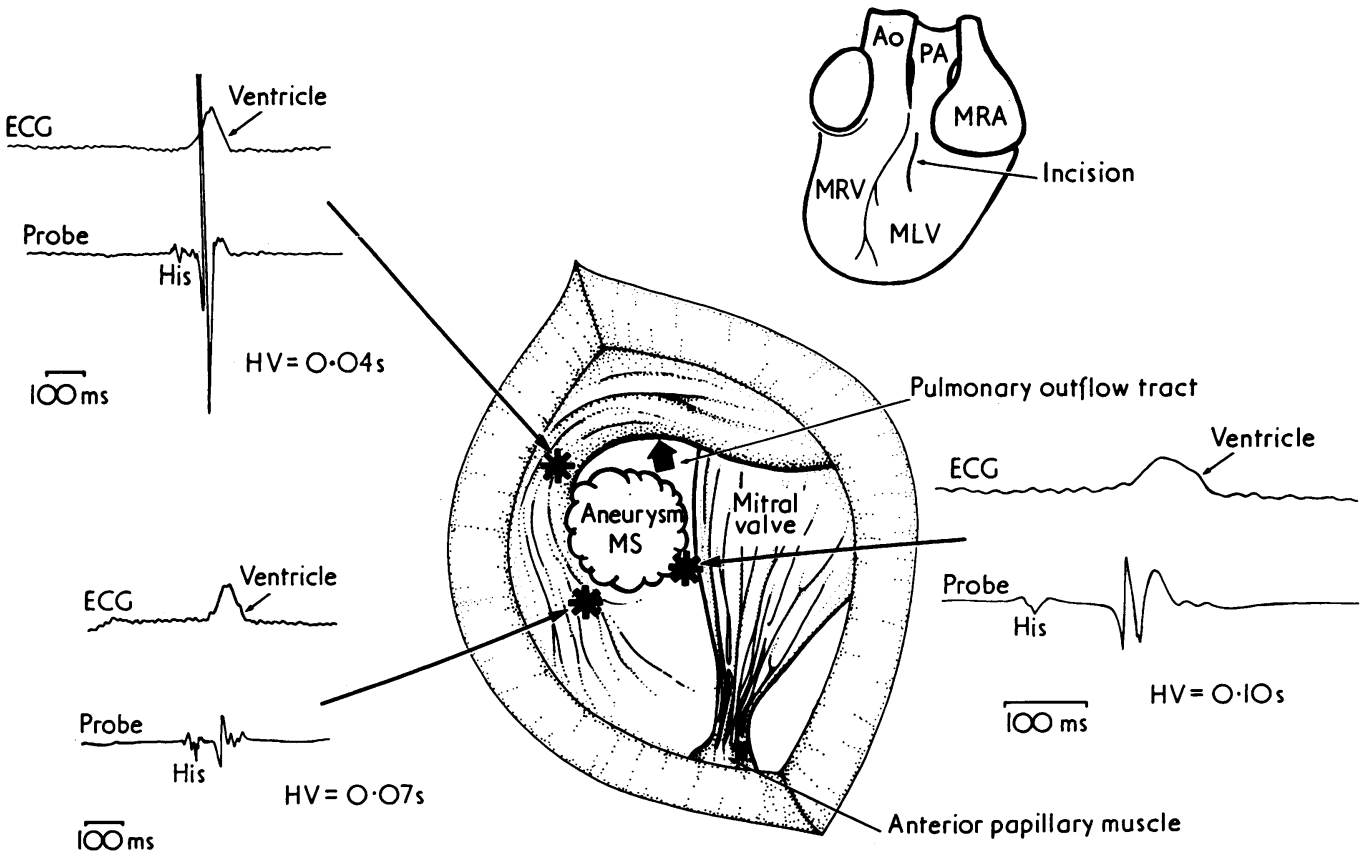

Fig. 6 Diagram of operative findings in case 3 showing morphological left ventricle seen through ventriculotomy and His bundle electrograms recorded from the points indicated by asterisks (compare with Fig. $3 \mathrm{~A}$, case 1 ). 
surgeon to identify the atrioventricular bundle by intraoperative mapping before surgically correcting associated defects in such hearts.

We are grateful to our clinical colleagues for permitting us to publish details of cases previously under their care, particularly Professor J. D. Hay, Dr. R. S. Jones, and Dr. J. Shackleton of the Royal Liverpool Children's Hospital, and Dr. M. Goldberg of Groby Road Hospital, Leicester.

We also wish to acknowledge the help and support given by Professor F. Harris, in allowing us facilities in the Institute of Child Health, University of Liverpool.

\section{References}

Allwork, S. P., Bentall, H. H., Becker, A. E., Cameron, H., Gerlis, L. M., Wilkinson, J. L., and Anderson, R. H. (1976). Congenitally corrected transposition of the great arteries. Morphologic study of 32 cases. American fournal of Cardiology, 38, 910-923.

Anderson, R. H., Arnold, R., and Jones, R. S. (1972). Dbulboventricular loop with L-transposition in situs inversus. Circulation, 46, 173-179.

Anderson, R. H., Arnold, R., Thapar, M. K., Jones, R. S., and Hamilton, D. I. (1974a). Cardiac specialised tissue in hearts with an apparently single ventricular chamber (double inlet left ventricle). American fournal of Cardiology, 33, 95-106.

Anderson, R. H., Arnold, R., and Wilkinson, J. L. (1973). The conducting system in congenitally corrected transposition. Lancet, 1, 1286-1288.

Anderson, R. H., Becker, A. E., Arnold, R., and Wilkinson, J. L. (1974b). Conducting tissues in congenitally corrected transposition. Circulation, 50, 911-923.

Dick, M., Van Praagh, R., Rudd, M., Folkerth, T., and Casteneda, A. R. (1977). Electrophysiological delineation of the specialised atrioventricular conduction system in two patients with corrected transposition of the great arteries with situs inversus (I.D.D.). Circulation, 55, 896-900.

Ellis, K., Morgan, B. C., Blumenthal, S., and Anderson, D. H. (1962). Congenitally corrected transposition of the great vessels. Radiology, 79, 35-49.

Kaiser, G. A., Waldo, A. L., Beach, P. M., Bowman, F. O., Hoffman, B. F., and Malm, J. R. (1970). Specialized cardiac conduction system improved electrophysiological identification technique at surgery. Archives of Surgery, 101, 673-676.

Kupersmith, J., Krongrad, E., Gersony, W. M., and Bowman, F. O. (1974). Electrophysiologic identification of the specialized conducting system in corrected transposition of the great arteries. Circulation, 50, 795-800.

Lev, M., Licata, R. H., and May, R. C. (1963). The conduction system in mixed levocardia with ventricular inversion (corrected transposition). Circulation, 28, 232-237.

Maloney, J. D., Ritter, D. G., McGoon, D. C., and Danielson, G. K. (1975). Identification of the conduction system in corrected transposition and common ventricle at operation. Mayo Clinic Proceedings, 50, 387-394.

Shinebourne, E. A., Macartney, F. J., and Anderson, R. H. (1976). Sequential chamber localisation. British Heart fournal, 38, 327-340.

Smith, A., Yen Ho, S., and Anderson, R. H. (1977). Histological study of the cardiac conducting system as a routine procedure. Medical Laboratory Sciences, 34, 223-229.

Thiene, G., Nava, P., and Rossi, L. (1977). The conducting tissue in corrected transposition in situs inversus. European fournal of Cardiology, 6, 57-70.

Waldo, A. L., Pacifico, A. D., Bargeron, L. M., James, T. N., and Kirklin, J. W. (1975). Electrophysiological delineation of the specialized A-V conduction system in patients with corrected transposition of the great vessels and ventricular septal defect. Circulation, 52, 435-441.

Requests for reprints to Dr. J. L. Wilkinson, Institute of Child Health, Department of Child Health, Alder Hey Children's Hospital, Liverpool L12 2AP. 